\title{
AVANCES EN LA INVESTIGACIÓN COLABORATIVA Y CONTROL INTEGRADO DE LA "HOJA DE HOZ" EN LOS CULTIVOS DE OLIVO DE TACNA Y ARICA
}

\author{
René Chávez Alfaro', Eloy Casilla Garcia', Luis Salazar ${ }^{2}$ \\ Germán Sepulveda ${ }^{3}$, Alfredo Huarachi ${ }^{1}$, Ida Bartolini ${ }^{2}$
}

\section{RESUMEN}

Las zonas agroecológicas áridas y salinas del norte de Chile y sur del Perú presentan un enorme potencial agrícola para el cultivo y explotación agro-industrial de variedades mejoradas y comerciales de olivo (Olea europaea). Más de 5000 hectáreas de olivo de las variedades Azapeña y Sevillana son cultivadas en las zonas desérticas de Tacna y Arica. Estas variedades han mostrado en forma sostenible una remarcable adaptación y tolerancia a los estreses abióticos más comunes de estos suelos desérticos, tales como salinidad, toxicidad de boro y riego restringido. Sin embargo, algunos estreses bióticos como las plagas insectiles Orthesia y Margaronia siguen siendo un problema muy serio en el cultivo del olivo.

Durante los dos últimos años se ha venido realizando una investigación colaborativa entre el Centro Internacional de la Papa, la Universidad Nacional de Tacna y la Universidad de Tarapacá a nivel de campo y laboratorio sobre la frecuencia e intensidad de la enfermedad del follaje conocida como "HOJA DE HOZ DEL OLIVO". Los resultados de esta investigación muestran una disminución gradual y significativa del rendimiento comercial del olivo por efecto de esa enfermedad. Los análisis preliminares de ADN de los extractos de las hojas enfermas con síntomas de Hoja de Hoz muestran que el microorganismo patógeno causante de esa enfermedad sería un VIROIDE transmitido mayormente de planta a planta mediante injertos y podas. Dentro del sistema del control integrado de esa enfermedad se plantea la utilización masal y comercial de ṕlántulas in vitro y yemas de injertos libres de patógenos generados en un programa de biotecnología para zonas áridas.

\section{$A B S T R A C T$}

The arid agroecological zone from northem Chile and southern Perú has a great agricultural potential to grow olives (Olea europaea) and exploit it in the processing industry. There are more than 5000 hectares folive plantations from commercial varieties Sevillana and Azapeña in the coastal desertic valleys of Tacna and Arica. These varieties have shown remarkable adaptation and tolerance to the most common abiotic stresses from arid soils such as salinity, boron toxicity and restricted irrigation. However some biotic desert stresses, like the insect pests Orthesia and Margaronia are still very serious problems in the explotation of olives.

During the last two years a collaborative research project between the International Potato Center the National University of Tacna and the Univerity of Tarapacá has been undertaken on the occurrence and frequency of the foliage disease known as "SICKLE LEAF OF OLIVE". Up to date results shows that this disease may cause a gradual and significative yield reduction in the infected olive tree. DNA analysis from diseased leaf extracts shows that the microorganism involved in this desease coud be a VIROID, which is mainly transmitted by grafts and pruning. The IPM system should include the utilization of a mass and commercial production and distribution of pathogen free in vitro buds and plantlets of vaieties Sevillana and Azapeña, which should be generated though the establishment of an alive biotechnological program for arid zones.

\footnotetext{
Facultad de Ciencias Agricolas,, Universidad Nacional Jorge Basadre Grohmann, Tacna-Peni.

Centro Internacional de la Papa, Lima, Perú.

Facultad de Agronomia, Universidad de Tarapacá, Arica-Chile.
} 


\section{INTRODUCCIÓN}

El origen y evolución del olivo cultivado, Olea europaea, $2 n=2 x=46$, se inicia hace más de 6000 años en las zonas agroecológicas semiáridas y sub tropicales de Asia Menor y en la cuenca del Mediterráneo. La existencia actual de una inmensa variabilidad genética intraespecífica en el olivo cultivado en el mundo se materializa en cientos de variedades y ecotipos, muchos de las cuales se habrian originado en sucesivas hibridaciones interespecíficas espontáneas entre las diferentes especies del género Olea. Genotipos superiores 0 híbridos promisorios originados de estas hibridaciones interespecíficas y que mostraban conspicuos atributos agronómicos fueron selecionados y clonados inconscientemente por los antiguos agricultores del viejo mundo a través del tiempo y del espacio. Gracias a la remarcable estabilidad genética propia de esta especie, estos genotipos promisorios 0 híbridos primitivos clonados se han mantenido hasta nuestros días. La especie Olea europaea cuenta con cerca de 2000 variedades nativas y mejoradas, siendo Italia el país con mayor diversidad genética de olivo con 500 variedades registradas de olivo (Vegari, et at, 96).

El extremo norte del desierto de Atacama comprendido entre Arica y Tacna entre los $18^{\circ}$ y $19^{\circ}$ Latitud Sur, representa una de las zonas agroecológicas áridas y salinas de mayor extensión y explotación del olivo, Olea europaea, $2 n=2 x=46$, con un potencial total de 11000 hectáreas de cultivo. Durante los últimos 40 años, cerca de 25 variedades de olivo del Viejo Mundo, especialmente de España, fueron introducidos en esta zona, de las cuales solamente las cinco variedades Sevillana, Empeltre, Ascolana, Pendolino y Azapeña, han mostrado una remarcable adaptación y tolerancia a los estreses abióticos, climáticos y edáficos más comunes del desierto costero, tales como altas temperaturas, extrema aridez, salinidad y niveles tóxicos de boro en el suelo. (Chávez et. al. 1995, Casilla 1999).

\section{ESPECTRO DE VARIABILIDAD GENETICA}

La gran diversidad genética del olivo, las numerosas sinonimias y homonimias, así como la existencia de grupos de variedades con características morfológicas similares, han limitado el proceso de clasificación e identificación de muchas variedades introducidas en América desde la época de la Conquista hasta nuestros días.

Las variedades comerciales Sevillana y Azapeña ocupan más del $90 \%$ del área total del olivo cultivado en Tacna y Arica. Esta amplia extensión de cultivo de estas dos variedades es debida principalmente, a los grandes atributos agro-industriales que tienen. Entre estos atributos cabe destacar la precocidad, alto rendimiento, buena arquitectura de la planta y excelente calidad para procesamiento industrial y exportación. Sin embargo, hasta ahora las técnicas basadas en modelos morfológicos no han logrado todavía resolver del todo el problema de diversa identidad genética de las variedades Azapeña, Arauco y Sevillana cultivados comercialmente en Sudamérica.

Basado en algunas preliminares evidencias genéticas y descriptores morfológicos del olivo, recientemente, Chávez, R. y Casilla $\mathrm{E}$ (Comunicación personal) han planteado la hipótesis de que las variedades Sevillana y Azapeña, cultivadas en Tacna, Arica, Ilo, Llauca, Acarí y Vallemar, así como la variedad Arauco cultivada en el centro y norte de Argentina se habrian originado a partir de un solo clon o un mismo genotipo introducido hace mucho tiempo en Sudamérica desde Sevilla, España. Las investigaciones futuras a corto y mediano plazo con el uso intensivo de marcadores moleculares ADN determinarán, definitivamente ${ }^{1}$, la real naturaleza genética de estos tres cultivares de olivo de enorme potencial de explotación y exportación en Sudamérica. Los marcadores ADN como RAPD, AFLP y SSR son muy precisos en el análisis genómico de la planta y no se ven afectados por factores ambientales edáficos y climáticos ni por las diferentes fases fenológicas de la planta de olivo (Vergari ed. al 96).

\section{ESTRESES BIOTICOS DEL OLIVO}

Numerosas plagas y enfermedades del olivo han sido identificadas y estudiadas en las plantaciones de olivo de Tacna y Arica. Asimismo se han generado y difundido paquetes tecnológicos para el control integrado, principalmente de las siguientes plagas que atacan a las ramas y follaje del olivo: Acaro del olivo, Gusano de la flor, Gusano del brote, Barrenillo del tallo, la Quereza Blanca y la Quereza Negra del olivo. Entre las enfermedades más comunes del follaje que se han estudiado se tiene la muerte 
descendente (Verticillium dahliae), la Fumagina (Fumago conodium), y los nemátodos del nudo de la raíz del gènero Meloidogyne y de la corteza de la raiz del género Pratylenchus. De igual manera la deformación foliar del olivo, muy conocida por los olivicultores como "Hoja de hoz", ha sido frecuentemente mencionada por los agricultores y profesionales agrónomos de la zona.

El nombre de "Hoja de Hoz" es descriptivo para esta enfermedad del follaje del olivo debido a la forma curvada o de hoz que muestra la hoja afectada con esta enfermedad (foto1). La enfermedad es común en todas las variedades comerciales de olivo que se cultivan en Sudamérica. Hay algunas evidencias de la existencia de "Hoja de Hoz" en los cultivos de olivo en Italia y Portugal (Thomas 1958, Waterwurth y Monroe 1975), indicando una reducción en la longitud de las ramas afectadas y reducción en el grado de fructificación (Thomas 1958).

El olivo, como toda planta de propagación asexual o vegetativa, es susceptible a infecciones viróticas o fitoplasmas, aunque su incidencia e importancia económica no es significativa en comparación con las enfermedades viróticas en los árboles frutales y plantas tuberíferas como la papa (Salazar, 1995). A la fecha se han identificado y descrito cerca de 13 especies de virus que infectan al olivo (Henriques,M.I.C, 1994, Barranco et.al,1999). De este grupo, cinco especies son virus muy polifagos y los resultantes parecen ser especificos del olivo, aunque uno de ellos (virus latente del olivo) se ha detectado en citricos de Italia y Turquía (Barranco et. al, 1999). No se conoce en forma exacta los vectores animales implicados en la dispersión natural de estos virus, aunque algunos de ellos se han observado en el polen, lo que sugiere una posible via de transmisión, la cual no ha sido comprobada experimentalmente (Martinelli y Gallitelli, 1985). Sin embargo, a pesar del desconocimiento de estos virus, algunas instituciones de producción y distribución de semilla de olivo de Italia y Portugal ya han iniciado programas para la certificación del material de plantación libre de virus.

En los últimos diez años se han descrito en Italia cuatro fitoplasmas asociados con olivos afectados por brotaciones anuales, deformaciones de hojas, brotes, entrenudos cortos y clorosis foliar (Barranco et. al. 1999). La patogenicidad de estos agentes no ha sido determinada completamente y se desconoce su difusión e importancia económica en las plantaciones de olivo.

\section{SINTOMATOLOGÍA}

La mayoria de los virus del olivo están asociados a algún tipo de alteración en las plantas a las que parasitan, lo que suele dar lugar a pérdidas cualitativas y/o cuantitativas (Clara, E.et. al. 1997). Las variedades Ascolana y Negrinha presentan malformaciones de los frutos reduciendo su calidad. Por otra parte, las estaquillas procedentes de árboles infectados tienen una escasa capacidad de enraizamiento en comparación con las estaquillas no infectadas y libres de virus. Clara y Asociados (1997) plantean que la virosis en el olivo afecta al vigor y longevidad de los árboles, así como a su capacidad de resistencia frente a estreses bióticos y abióticos. Asimismo, se han aislado virus en olivos que no tenian síntomas aparentes, lo que indica claramente que las pérdidas potenciales dependen del cultivar y/o de la cepa del virus presente. (Clara. et. al. 1997).

Los resultados de las evaluaciones de campo y trabajos comparativos entre árboles sanos con hojas normales y árboles afectados con la enfermedad de "Hoja de hoz" muestran en general los siguientes sintomas:

- Forma curvada o de hoz del limbo foliar

- Reducción del tamaño y área foliar de la hoja

- Alta frecuencia de clorosis en las hojas enfermas

- Crecimiento muy lento de la planta (enanismo) y vigor del follaje muy bajo.

- Las ramas afectadas presentan enanismo y reducción de los entrenudos (Foto 2).

- La copa del árbol toma la forma arrepollada en un estado avanzado de la enfermedad.

- Reducción en el grado de floración (Foto 3).

- Reducción en el grado de fructificación

No se han detectado síntomas de la enfermedad en los frutos de plantas enfermas. A pesar de que la enfermedad "Hoja de hoz" parece ser sistémica, se ha detectado una variabilidad sintomática dentro de la misma planta. No todas las ramas de la planta enferma muestran los síntomas de la enfermedad en las ramas y hojas, asimismo, el número de ramas asintomáticas en plantas enfermas varían entre árbol y árbol. 


\section{FRECUENCIA DE LA ENFERMEDAD}

Hasta la fecha se han realizado observaciones preliminares de campo en un total aproximado de 1000 plantas o árboles en estado de producción de las variedades Sevillana y Azapeña en Tacna y Arica. Las evaluaciones de campo se han basado en la sintomatología general de "Hoja de hoz" de los árboles utilizando la escala arbitraria de $0,1,3,5,7,9$ referida al porcentaje de ramas afectadas, en la siguiente forma:

\begin{tabular}{|c|l|}
\hline Escala & \multicolumn{1}{|c|}{ Descripción } \\
\hline 0 & Planta con $100 \%$ de ramas sanas \\
\hline 1 & Planta con $1-20 \%$ de ramas enfermas \\
\hline 3 & Planta con $21-40 \%$ de ramas enfermas \\
\hline 5 & Planta con $41-60 \%$ de ramas enfermas \\
\hline 7 & Planta con $61-80 \%$ de ramas enfermas \\
\hline 9 & Planta con $81-100 \%$ de ramas enfermas \\
\hline
\end{tabular}

De un total de aproximadamente 1000 árboles observados y evaluados, utilizando esta escala, cerca de un $80 \%$ de árboles no presentan síntomas de "Hoja de hoz" (plantas sanas). Sin embargo, cerca de un $20 \%$ de plantas (aprox. 200) mostraron síntomas de "Hoja de Hoz" que fluctúan entre el grado 1 al 9 de la escala. De esta población, más del $70 \%$ de plantas enfermas muestran sintomas en la escala 1 , es decir, $1-20 \%$ de ramas enfermas por árbol.

Observaciones preliminares realizadas de la sintomatología de "Hoja de hoz" en cerca de 1500 plantones y estacas prendidas en los diferentes viveros de olivo ubicados en el valle de Tacna han mostrado una frecuencia aproximada de $10 \%$ de plantones con síntomas a "Hoja de hoz" en las ramas y yemas terminales.

\section{AGENTE CAUSAL}

Algunas deformaciones de las hojas del olivo en forma de Hoja de hoz causadas por el ataque de ácaros de la especie Ditrimachus athiasella Keifer han sido detectadas en las plantaciones de olivo en la zona de Copiapó, Chile (Jiménez M.et al.1989). Sin embargo esta especie de ácaro no ha sido encontrada en los árboles evaluados en Azapa y Tacna con síntomas de la Hoja de hoz.

La Hoja de hoz es causada por un agente patógeno desconocido, aunque anteriormente la
"Hoja de hoz" en las plantas de olivo ha sido atribuida al ataque de ácaros, querezas, infección de virus y a una deficiencia de boro. En general, los síntomas parecen indicar que se trata de una enfermedad virótica; $\sin$ embargo, no hay evidencias experimentales que apoyen esta hipótesis. Experimentos de laboratorio realizados por Waterworth y Monroe (1975) con extractos de hojas enfermas, no mostraron partículas de virus ni de agentes microscópicos semejantes a fitoplasmas.

Thomas (1958) y Waterworth-Monroe (1975) reportaron que el periodo de incubación de este patógeno varía de siete meses a tres años, dependiendo de la variedad inoculada. Todo parece indicar que el desarrollo de esta enfermedad en una planta de olivo es lenta y progresiva. Extractos de hojas enfermas con "Hoja de hoz" inoculadas a tejidos de otras especies cultivadas como en aji, tomate, tabaco, papa y a la maleza Datura, no desarrollan ni muestran sintomas de esta enfermedad.

Recientes investigaciones de laboratorio con pruebas serológicas y observaciones al microscopio electrónico realizadas por el Dr. Luis Salazar (Comunicación personai) con extractos de hojas enfermas muestran a un agente patógeno similar a un viroide, el cual se trasmite de planta a planta por medio de injertos, podas y recolección de aceituna. Este mismo microorganismo ha sido detectado en extractos de hojas sanas (sin síntomas) colectadas en el Valle de Tacna, lo cual indica que algunas plantas o árboles sanos ya tienen una infección inicial del microorganismo patógeno.

\section{CONTROL}

La principal vía de transmisión de los virus del olivo es, probablemente, el uso de material vegetal infectado. Los virus SLVR y CMV del olivo, por ejemplo, pueden invadir la planta de manera sistémica, dado que se han detectado en todos los órganos de la planta (Rei et. al. 1993)

En vista que el presente trabajo de investigación es un estudio preliminar, no se puede todavía establecer medidas de control integrado de esta enfermedad. Sin embargo, las primeras evidencias encontradas sugieren la posibilidad de poder controlar esta enfermedad en la siguiente forma:

1. Multiplicación y propagación con yemas y estacas de plantas totalmente sanas. (Identificación de plantas madres). 
2. Desinfección con hipoclorito de calcio (5\%) de las herramientas utilizadas en las podas e injertos.

3. Utilización de yemas y plántulas generadas dentro de un programa de micropropagación masal, aplicando el sistema de cultivo in vitro de tejidos libres de patógenos.

\section{REFERENCIAS BIBLIOGRÁFICAS}

BARRANCO, R.; FERNÁNDEZ; ESCOBAR, L.; RALLO. (1999). Cultivo del olivo. 3a edic., Ediciones Mundi-Prensa, Madrid, pp.1-701.

CASILLA, E. (1999). "EI Cultivo del olivo en el valle de Tacna". Revista Agronómica. No1, pp 3-4.

CLARA M.I.E., REY F.T., FELIX, M.R., LEITAO, F.A., SERRANO, J.F., POTES, M.F. (1977). "Virosis que afectan a Olea Europaea L. y técnicas del diagnóstico". OLIVE, N ${ }^{\circ} 66$, pp 56-60.

CHAVEZ, R.; MENDOZA, H.; ESPINOZA, J. (1995). "Breeding Sweet Potato For Adaptation To Arid And Saline Soils". CIP-Circular 1995, pp 1-4

HENRIQUES, M.I.C (1994). "Viris diseases of Olive: An overlook". Acta Horticulturae, 356: 379-385.

JIMENEZ, M.; VARGAS, H.; BOBADIULLA, D.; GALLO, P. (1989) "Presencia del ácaro Phyllocoptruta Oleivora
Con la utilización promisoria de sondas de ADN de una hebra y sondas de ARN a corto y/o mediano plazo se podrá identificar y conocer la naturaleza sub microscópica de este patógeno, lo cual contribuirá efectivamente para el establecimiento de un programa de Control Integrado de la enfermedad de "Hoja de la Hoz" en los olivares en Tacna, Arica, e Ilo.
(Ashmend) (Acarina, Eriophydae) en la lil Región de Chile, Copiapó". Rev, IDESIA, VOL II.53-55

MARTELLI, G.P.; y GATELLI, D. "Virosis dell Olivo". L'Italia Agric, $122(2): 150-156$.

REI, F.T.; HENRIQUES, M.I.C; LEITAO, F.A.; SERRANO, J.F.; POTES M.F. (1993). Inmunodiagnosis of Cucumber Mosaic Cucumovirus in Different Olive Cultivars. OEPP/ EPPO Bull, 23: 501-504.

SALAZAR, L. (1995). Los virus de la papa y su control. Edic. Centro Internacional de la Papa.

THOMAS, H.E. (1958). "Sickle Leaf of Olive". Plant Dis. Rep.p. 42: 1154

VERGARI, G.; PATUMI, M.; FONTANAGA, G. (1996). Utilización de los marcadores rápidos para la caracterización del Germoplasma de Olivo. Olivae, 60: 19-22.

WATERWORTH, H. E.; y Monroe, R. L. (1975). "Graft Transmission of Olive Sickle Leaf Disorder". Plant Dis. Rep. 59: 366-367.

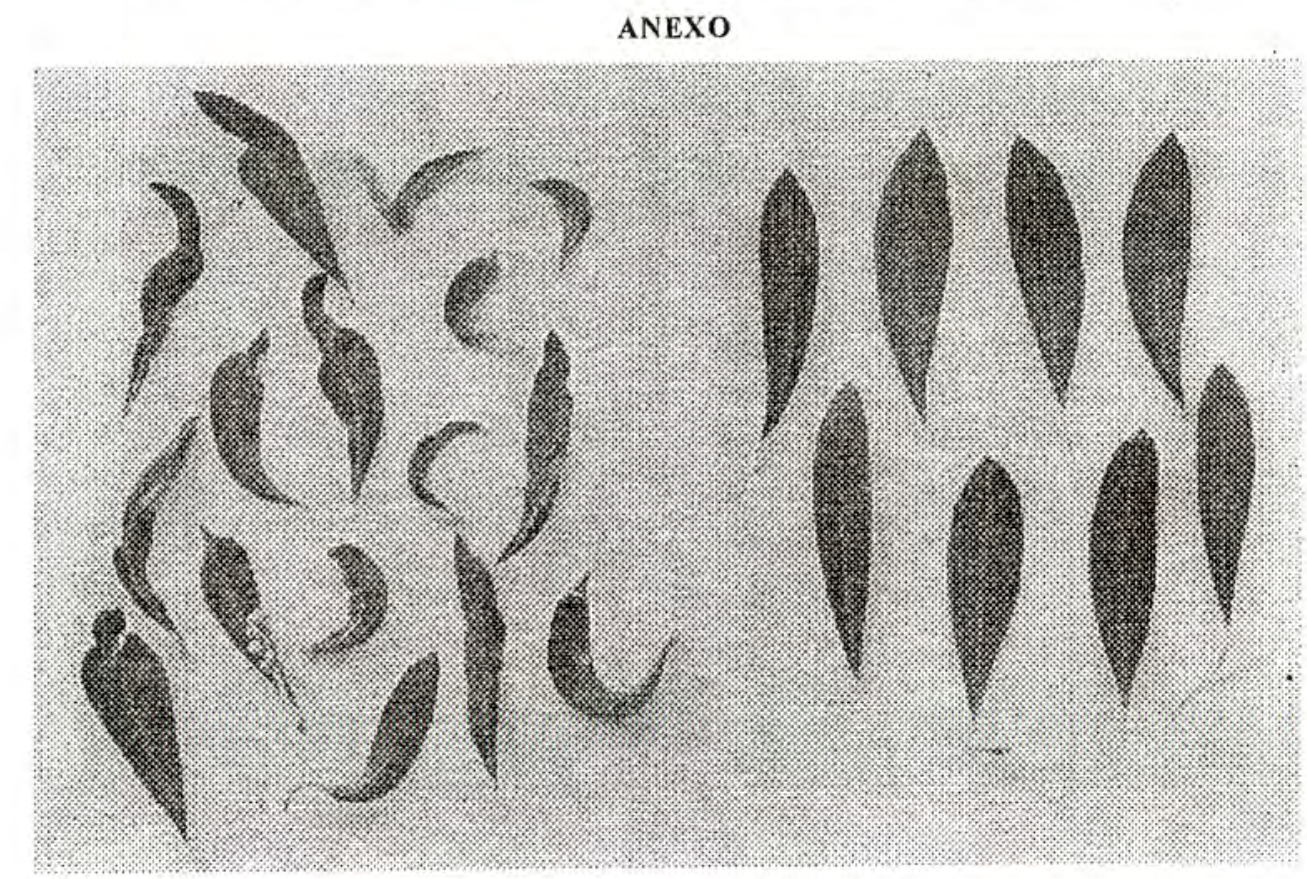

Foto 1. Hoja deformes por la enfermedad de "Hoja de hoz" de olivo (izquierda). A la derecha hojas normales sanas 
Ciencia \& Desarrollo 7

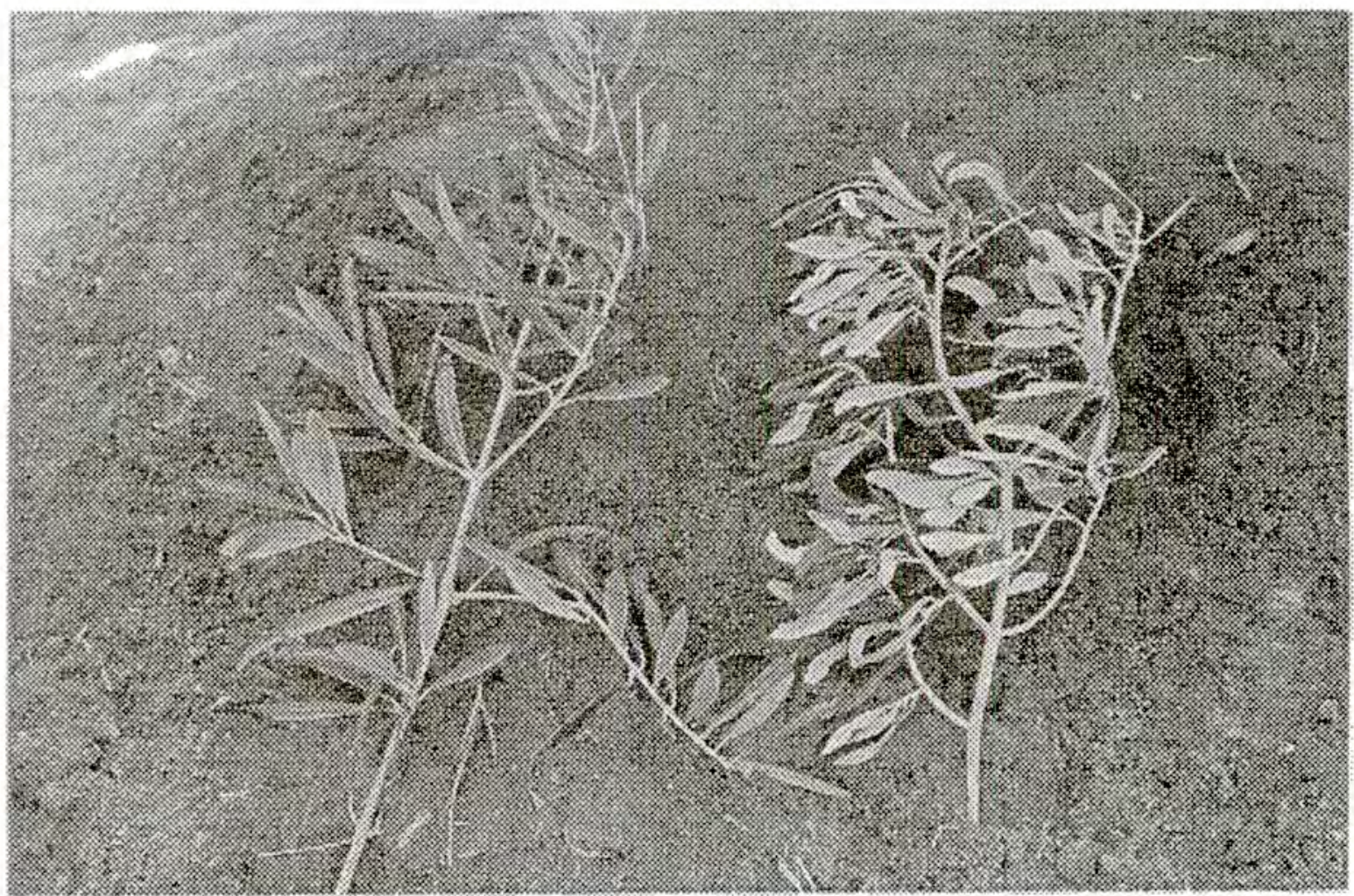

Foto 2. Rama de olivo con hojas sanas (izquierda) y rama con la enfermedad de "Hoja de Hoz" (derecha).

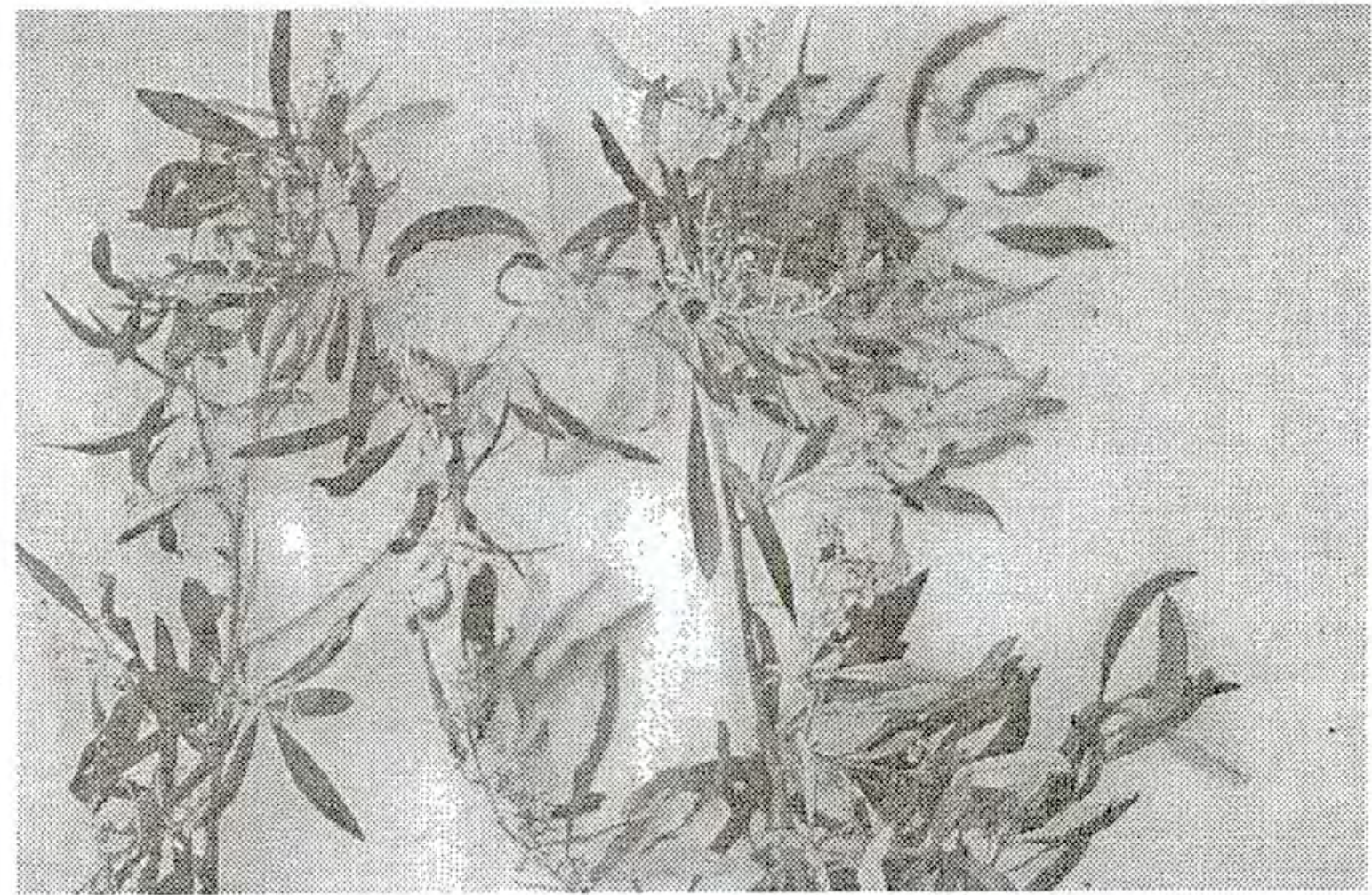

Foto 3. Reducción del área foliar y del grado de floración en una planta con el viroide. 